\title{
Novel Triiodide PVC-Based Membrane Sensor Based on a Charge Transfer Complex of Iodine and Bis(2-hydroxyacetophenone)butane-2,3-dihydrazone
}

\author{
Mohammad Reza Ganjali, ${ }^{*}$ Parviz Norouzi, Simindokht Shirvani-Arani, and Masoud Salavati-Niasari ${ }^{\dagger}$ \\ Department of Chemistry, Tehran University,Tehran,Iran.*E-mail: Ganjali@khayam.ut.ac.ir \\ †Department of Chemistry, Kashan University, Kashan, Iran \\ Received August 8, 2005
}

\begin{abstract}
In this study a novel triiodide ion-selective electrode based on a charge transfer complex of iodine and Bis(2-hydroxyacetophenone)butane-2,3-dihydrazone (ICT), as a membrane carrier was prepared. The electrode has a linear dynamic range between $1.0 \times 10^{-2}$ and $5.0 \times 10^{-7} \mathrm{M}$, with a Nernstian slope of $58.99 \pm 0.3 \mathrm{mV}$ decade $^{-1}$ and detection limit of $3.0 \times 10^{-7} \mathrm{M}$. The potentiometric response of the proposed sensor is independent of the $\mathrm{pH}$ of the solution in the $\mathrm{pH}$ range of 3.0-10.0. The electrode possesses the advantages of short conditioning time, fast response time, and especially, very good selectivity over a large number of common organic and inorganic anions. The electrode can be used for at least 6 months without any considerable divergences in the potentials. It was used as an indicator electrode in potentiometric titration of triiodide ion with thiosulfate.
\end{abstract}

Key Words : Triiodide ion-selective electrode, PVC membrane, Bis(2-hydroxyacetophenone)butane-2,3-dihydrazone, Potentiometry

\section{Introduction}

The conventional anion-selective electrodes based on quaternary ammonium or phosphonium salts, always display the so-called Hofmeister selectivity pattern. ${ }^{1}$ Since the 1980 's, research on anti-Hofmeister anion selective membrane electrodes have been more and more interested. Recently, electrodes based on transitional metal complexes, mettaloporphyrin and organometallic compounds have been reported. $^{2-14}$ These electrodes demonstrate potentiometric anion selectivity sequences apparently deviating from the Hofmeister sequences. Such deviation results from the unique interaction of the central metals of the complexes, with the target anion, rather than from the hydration free energy and the relative solubility of the individual anions in the solvent mediator.

We have recently introduced several PVC-based membrane sensors for different anions such as sulfate, thiocyanate, bromide, iodide, phosphate, and chloride ions with good selectivities. ${ }^{15-25}$ In spite of the vital importance of triiodide determination in the chemical, and industrial analyses, only seven triiodide sensors have been reported, all of which suffered from relatively high detection limits, and some significant interferences from some common organic and inorganic anions. ${ }^{25-30}$ Thus, we were interested in the preparation of a new solvent polymeric membrane sensor for selective monitoring of triiodide ion in solutions. In this paper we wish to report a highly selective triiodide PVC membrane sensor, based on a new charge-transfer complex between iodine and Bis(2-hydroxyacetophenone)butane2,3-dihydrazone as excellent ion-carrier for monitoring trace amounts of triiodide.

\section{Experimental Section}

Reagents. Reagent grade dibutyl phthalate (DBP), nitrobenzene (NB), benzyl acetate (BA), acetophenon (AP), $o$ nitrophenyloctyl ether (NPOE), iodine, tetrahydrofuran (THF), hexadecyltrimethylammonium bromide (HTAB), and high relative molecular weight PVC (all from Merck) were used as received. The potassium and sodium salts of all anions used (all from Merck) were of the highest purity available and used without any further purification except for vacuum drying over $\mathrm{P}_{2} \mathrm{O}_{5}$. Doubly distilled deionized water was used throughout.

Synthesis of Complex. The ITC was synthesized in three steps including the synthesis of 2,3-butane dihydrazone, the synthesis of Schiff's base and finally the synthesis of the charge transfer complex.

Step one, the synthesis of 2,3-butane dihydrazone: To a boiling solution of $11.63 \mathrm{~g}$ of aqueous hydrazine $(0.24 \mathrm{M})$ in $100 \mathrm{~mL}$ of methanol, were added $75 \mathrm{~mL}$ of biacetyl $(0.12$ mol, $10.33 \mathrm{~g}$ ), over a period of 120 minutes. Refluxing was continued for an additional 60 minutes. Then $200 \mathrm{~mL}$ of water were added and the methanol was removed by distillation. After cooling the resulting aqueous solution in an ice-bath, white crystals of the product were formed. These were filtered, washed with a little water, recrystalized from $100 \mathrm{~mL}$ of hot methanol, and dried in vacuum, m.p $158-159{ }^{\circ} \mathrm{C}$ (reported $158{ }^{\circ} \mathrm{C}$ ); yield $\sim 54 \%$. Anal. Cacd. For $\mathrm{C}_{4} \mathrm{H}_{10} \mathrm{~N}_{4}$ : C, 42.09; H, 8.83; N, 49.08.

Found: C, 42.16; H, 8.71; N, 49.74. IR $\left(\mathrm{KBr}, \mathrm{cm}^{-1}\right): 3330$, $3180\left(v_{\mathrm{N}-\mathrm{H}}\right) ; 1580\left(v_{\mathrm{C}=\mathrm{N}}\right), 1615\left(v_{\mathrm{NH} 2}\right)$.

Step two, the Schiff's base preparation: 2,3-Butanedihydrazone $(1.14 \mathrm{~g}, 0.01 \mathrm{~mol})$ was dissolved in $50 \mathrm{~mL}$ 

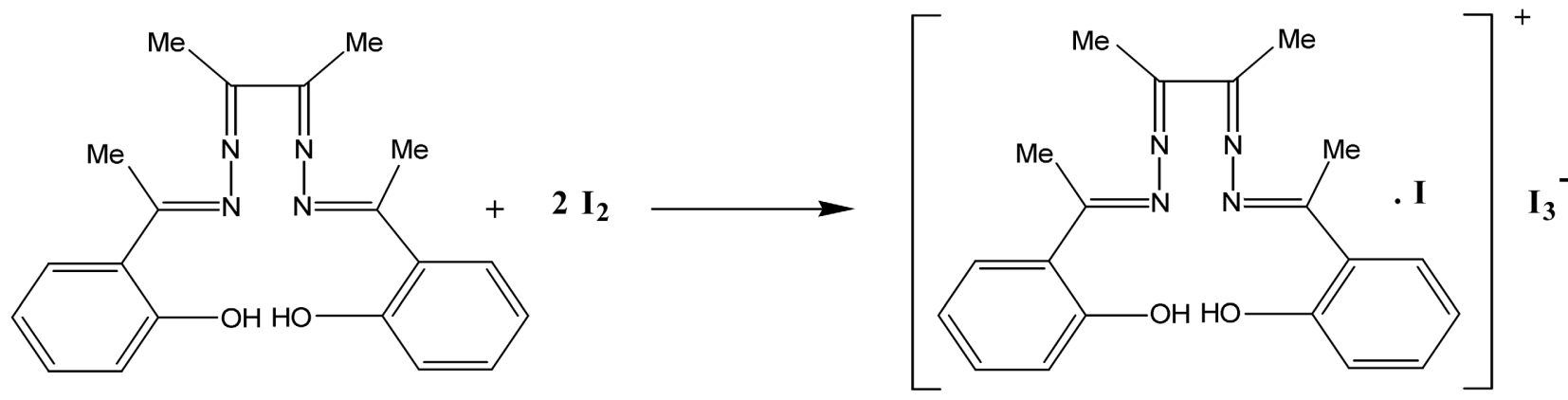

Figure 1. Chemical reaction of ICT preparation and chemical structure of ICT.

ethanol and then transferred into a $250 \mathrm{~mL}$ three necked flask. Under reflux $2.75 \mathrm{~g}(0.02 \mathrm{~mol})$ of 2-hydroxyacetophenone in $80 \mathrm{~mL}$ of ethanol were added drop wise to the flask. The stirred mixture was kept reacting for $3 \mathrm{~h}$ under reflux, and then cooled to room temperature. The solid product was filtered, and the product was recrystallized from chloroform. Yield $\sim 68 \%$. Anal. Cacd. For $\mathrm{C}_{20} \mathrm{H}_{22} \mathrm{~N}_{4} \mathrm{O}_{4}$ : C, 68.55; H, 6.33; N, 15.99. Found: C, 68.41\%; H, 6.26\%; N, 9.24\%. IR $\left(\mathrm{KBr}, \mathrm{cm}^{-1}\right): 3443\left(v_{\mathrm{O}-\mathrm{H}}\right) ; 1608,1575\left(v_{\mathrm{C}=\mathrm{N}}\right)$.

Step three, preparation of the triiodide complex: $\mathrm{I}_{2}$ and the obtained Schiff's base were separately dissolved in chloroform and were mixed with each other in mol ratio of $4: 1\left(\mathrm{I}_{2}\right.$ /Schiff's-base).

The mixture was placed in refrigerator for $24 \mathrm{~h}$ and the precipitated complex was then separated from solvent by filter paper.

Then the precipitate was recrystallized, and after one day, the complex was separated from the solvent and dried in an oven.

Electrode Preparation. The general procedure to prepare the PVC membrane was to mix thoroughly $63 \mathrm{mg}$ of BA, 30 $\mathrm{mg}$ of powdered PVC, $2 \mathrm{mg}$ of HTAB, and $5 \mathrm{mg}$ of ICT in 5 $\mathrm{mL}$ of fresh THF. The resulting mixture was transferred into a glass dish of $2 \mathrm{~cm}$ diameter. The solvent was evaporated slowly until an oily concentrated mixture was obtained. A Pyrex tube (3-5 mm o.d.) was dipped into the mixture for about $10 \mathrm{~s}$ so that a nontransparent membrane of about 0.3 $\mathrm{mm}$ thickness was formed. ${ }^{31-38}$ The tube was then pulled out from the mixture and kept at the room temperature for about $12 \mathrm{~h}$. The tube was then filled with an internal filling solution of $1.0 \times 10^{-3} \mathrm{M}$ triiodide $\left(1.0 \times 10^{-3} \mathrm{M} \mathrm{I}_{2}+1.0 \times\right.$ $10^{-3} \mathrm{M} \mathrm{I}^{-}$). The electrode was finally conditioned by soaking in $1.0 \times 10^{-3} \mathrm{M}$ triiodide solutions for $12 \mathrm{~h}$. A silver/silver chloride wire was used as an internal reference electrode.

EMF Measurements. All EMF measurements were carried out with the following assembly: A Corning ion analyzer $250 \mathrm{pH} / \mathrm{mV}$ meters was used for the potential measurements at $25.0 \pm 0.1{ }^{\circ} \mathrm{C}$. The EMF observations were made relative to a double-junction saturated calomel electrode (SCE, Philips), with its chamber filled with an ammonium nitrate solution. The activities were calculated according to the Debye-Huckel procedure. ${ }^{39}$

\section{Results and Discussion}

It is well established that the selective interaction between a given analyte anion and a lipophilic carrier within the membrane is essential for the development of anionselective polymeric membranes exhibiting anti-Hofmeister potentiometric selectivity patterns. ${ }^{1}$ In the case of the transition metal complexes, organometallic and metalloporphyrin compounds, the anion selectivity is mainly governed by the specific interaction between the central metal and anions rather than the lipophilicity of the anions or simple opposite charge interactions with anionis.

In the case of triiode sensor, charge transfer complex, ionpair association, and Mn (III)-porphyrin derivatives, have been used as specific ion carriers. ${ }^{25-30}$ These reported triiodide sensors, exhibited Nernstian behaviors, and relatively good selectivities. Thus, at first, ICT was used as an ion carrier in the construction of anionic membrane sensors, for a wide variety of common organic and inorganic anions, with different lipophilicities. The potential responses of various anion-selective electrodes based on the chargetransfer complex used, are given in Figure 2. As can be seen, with the exception of triiodide, all anions tested, show negligible responses in the concentration range of $5.0 \times 10^{-7}$. $1.0 \times 10^{-2} \mathrm{M}$. This can be due to their very weak interactions

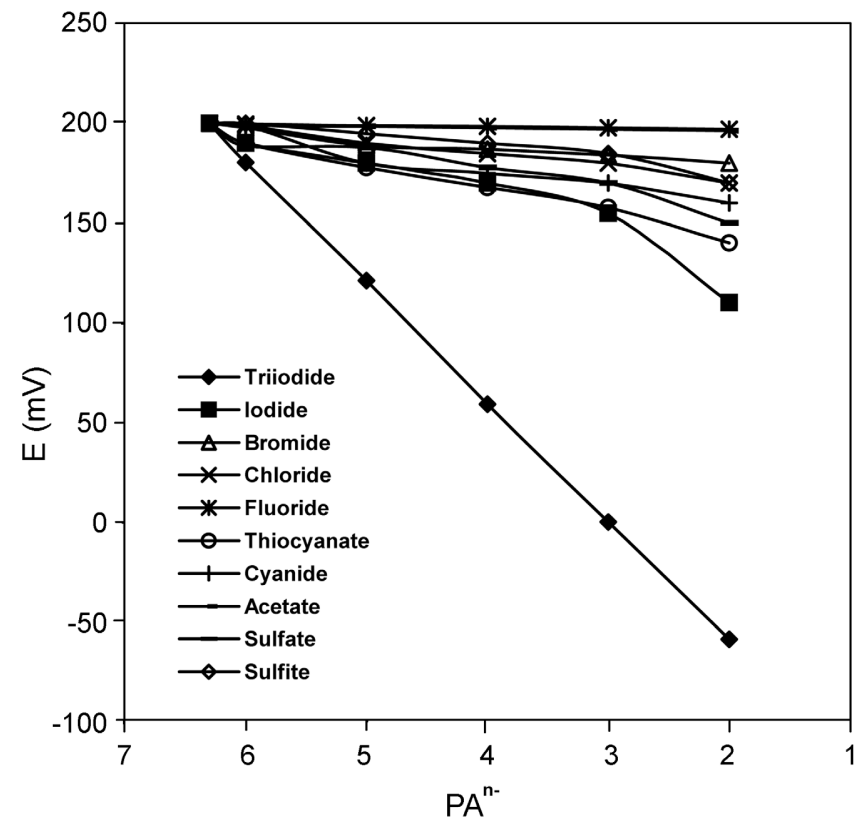

Figure 2. Potential responses of different ion-selective electrodes based on ICT. 
Table 1. Optimization of membrane ingredients

\begin{tabular}{ccccccc}
\hline \multirow{2}{*}{ Number } & \multicolumn{9}{c}{ Composition $\%$} & \multicolumn{2}{c}{$\begin{array}{c}\text { Slope } \\
(\mathrm{mV} \mathrm{decade})\end{array}$} & $\begin{array}{c}\text { Linear Dynamic } \\
\text { Range }\end{array}$ \\
\cline { 2 - 4 } & PVC & Plasticizer & HTAB & Ionophore & & $8.0 \times 10^{-7}-1.0 \times 10^{-2}$ \\
\cline { 2 - 5 } 1 & 30 & BA, 64 & 2 & 4 & $38.90 \pm 0.3$ & $5.0 \times 10^{-7}-1.0 \times 10^{-2}$ \\
2 & 30 & BA, 61 & 2 & 7 & $45.50 \pm 0.3$ & $5.0 \times 10^{-7}-1.0 \times 10^{-2}$ \\
3 & 30 & BA, 63 & 2 & 5 & $58.99 \pm 0.3$ & $5.0 \times 10^{-6}-1.0 \times 10^{-2}$ \\
4 & 30 & BA, 65 & - & 5 & $41.90 \pm 0.3$ & $2.0 \times 10^{-4}-1.0 \times 10^{-2}$ \\
5 & 30 & BA, 68 & 2 & - & $7.82 \pm 0.3$ & $5.0 \times 10^{-6}-1.0 \times 10^{-2}$ \\
6 & 30 & DBP, 63 & 2 & 5 & $50.72 \pm 0.3$ & $5.0 \times 10^{-5}-1.0 \times 10^{-2}$ \\
7 & 30 & NPOE, 63 & 2 & 5 & $14.90 \pm 0.3$ & $5.0 \times 10^{-6}-1.0 \times 10^{-2}$ \\
8 & 30 & AP, 63 & 2 & 5 & $12.50 \pm 0.3$ & $5.0 \times 10^{-5}-1.0 \times 10^{-2}$ \\
9 & 30 & NB, 63 & 2 & 5 & $14.10 \pm 0.3$ &
\end{tabular}

with the membrane. Figure 2 shows that among various anions tested, iodide exhibits a stronger response than other anions, at higher concentrations. This is most probably to some extent, due to the oxidation of iodide to triiodide ion. However, the triiodide membrane sensor revealed a Nernstian potential response in a wide concentration range $\left(5.0 \times 10^{-7}-1.0 \times 10^{-2} \mathrm{M}\right)$

It is well known that the membrane composition, and especially in some cases, the nature of the additive may have a significant influence on the sensitivity and selectivity obtained for a given ionophore. ${ }^{15-30}$ The performance characteristics of several membranes having ingredients of different proportions are summarized in Table 1. It is seen that membrane

No. 3 with an optimized composition of $30 \%$ PVC, $63 \%$ $\mathrm{BA}, 5 \%$ ICT and $2 \%$ HTAB results in the best sensitivity with a Nernstian slope of $58.99 \pm 0.2 \mathrm{mV}$ per decade concentration of triiodide ions over a very wide dynamic range.

As is obvious from Table 1, among the five solvent mediators used, BA with a very low polarity is a more effective solvent mediator than NPOE, NB, AP, and DBP in preparing the triiodide sensor. It should be noted that the nature of the plasticizer influences both the dielectric constant of the membrane, and the mobility of the ion carrier. This is due to the high lipophilicity of triiodide ions that can be easily extracted by the low polarity of solvent in the membrane.

The sensitivity of the electrode's response increases with increasing ion carrier ICT content, until a value of 5\% is reached. Further addition of ionophore will, however, result in diminished response of the electrode, most probably due to some inhomogenieties and possible saturation of the membrane. ${ }^{5}$

The data given in Table 1 reveal that the presence of additive has a beneficial influence on the performance characteristics of the membrane electrode. Addition of $2 \%$ hexamethytrimethylammonium bromide (HTAB) as a suitable additive, ${ }^{26-30,40,41}$ will increase the slope of the potential response of the sensor from a relatively poor value of 41.9 $\mathrm{mV}$ per decade (No. 4), to a Nernstian value of $58.99 \pm 0.2$ $\mathrm{mV}$ per decade (No. 3). The presence of cationic additives

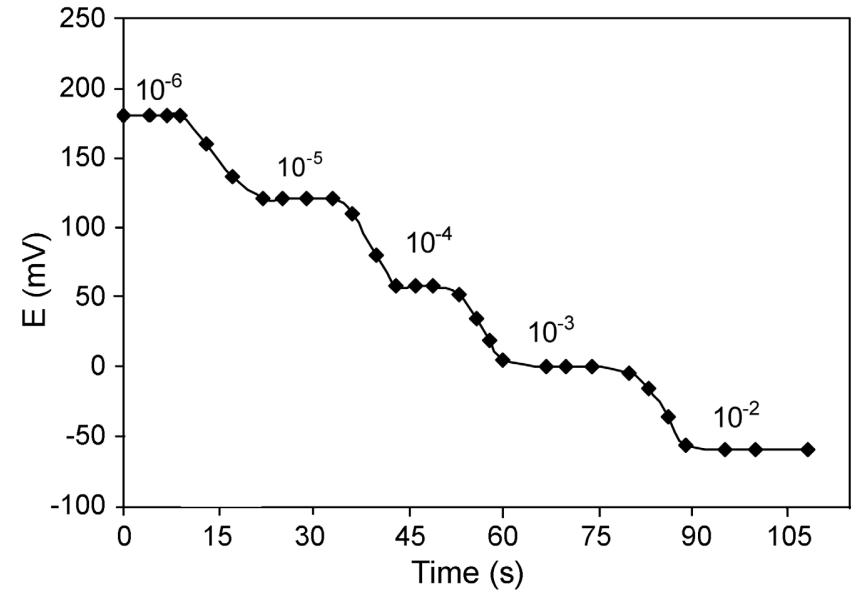

Figure 3. Calibration curves of triiodide electrode based on ICT. (No. 3).

such as HTAB can reduce the ohmic resistance and improve the response behavior and selectivity of the membrane electrodes. $^{42,43}$ Moreover, the additives may catalyze the exchange kinetics at the sample-membrane interface. ${ }^{44}$

The critical response characteristics of the electrode were assessed according to IUPAC recommendation. ${ }^{45}$ The EMF responses of the PVC membrane at varying concentrations of triiodide ion are shown in Figure 3. Figure 3 indicates a rectilinear range from $5.0 \times 10^{-7}$ to $1.0 \times 10^{-1} \mathrm{M}$. The slope of the calibration curve was $58.99 \pm 0.2 \mathrm{mV}$ per decade of triiodide concentration. The limit of detection, as determined from the intersection of the two extrapolated segments of the calibration graph, was $3.0 \times 10^{-7} \mathrm{M}$.

The average time required for the membrane electrode to reach a potential response within $\pm 1 \mathrm{mV}$ of the final equilibrium value alter successive immersions into a series of triiodide solutions, each having a 10 -fold difference in concentration, was also investigated. A potential-time plot for the electrode response is shown in Figure 4. As seen, the response times of the PVC membrane for low concentrations $\left(10^{-6}\right)$, and high concentration of triiodide ions, are less than 12 , and $10 \mathrm{~s}$ respectively. The standard deviation of 9 replicate measurements is $\pm 0.4 \mathrm{mV}$.

The $\mathrm{pH}$ dependence of the potential response of the 


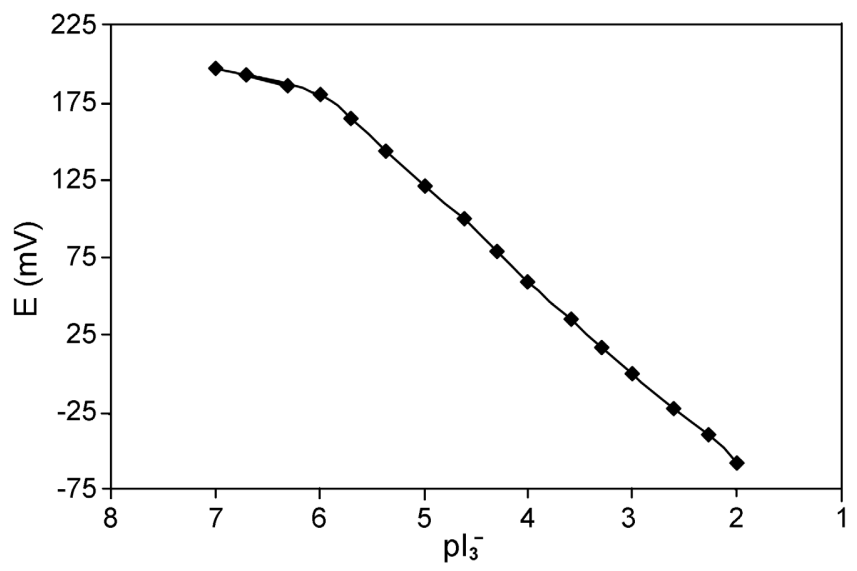

Figure 4. Dynamic response time of the triiodide electrode for step changes in Concentration of $\mathrm{I}_{3}^{-}$: A) $\left.1.0 \times 10^{-5} \mathrm{M}, \mathrm{B}\right) 1.0 \times 10^{-4} \mathrm{M}$, C) $1.0 \times 10^{-3} \mathrm{M}$, D) $1.0 \times 10^{-2} \mathrm{M}$.

proposed electrode in the $\mathrm{pH}$ range of 1.0-13 was also tested, and the results are shown in Figure 4. As can be seen, the potential response remains constant over the $\mathrm{pH}$ range of 3.0-10.0. In highly alkaline media, the potential decreases sharply, most probably due to the disproportion reaction between $\mathrm{I}_{3}{ }^{-}$and $\mathrm{OH}^{-}$that results in the formation of hypoiodate and iodide, ${ }^{46}$ both of which are insensitive to the membrane electrode. At $\mathrm{pH}$ values lower than 3.0, the electrode potential rises sharply. This is probably due to simultaneous response of the electrode to oppositely charged $\mathrm{H}_{3} \mathrm{O}^{+}$and $\mathrm{I}_{3}^{-}$ions.

One of the most important characteristics of an anionselective membrane electrode is its relative response, for the primary anion over other anions present in solution, which is usually expressed in terms of potentiometric selectivity coefficient. In this work, the matched potential method was used for the determination of the selectivity coefficients. ${ }^{47}$ According to this method, a specified activity (concentration) of the primary ion ( $\mathrm{A}=10^{-7}-10^{-5} \mathrm{M}$ of triiodide) is added to a reference solution $\left(5.0 \times 10^{-7} \mathrm{M}\right.$ of triiodide $)$, and the potential is measured. In a separate experiment, interfering ions $\left(\mathrm{B}=10^{-2}-10^{-4} \mathrm{M}\right)$ are successively added to an identical reference solution, until the measured potential matches the one obtained before the addition of primary ions. The matched potential method selectivity coefficient, $\mathrm{K}_{\mathrm{MPM}}$, is then given by the resulting primary ion to interfering ion activity (concentration) ratio. The resulting values are given in Table 2.

From the data given in Table 2, it is immediately obvious
Table 2. Selectivity coefficient of various interfering anions

\begin{tabular}{cc}
\hline Anion & $\mathrm{K}_{\mathrm{SEL}}$ \\
\hline $\mathrm{Br}^{-}$ & $2.5 \times 10^{-5}$ \\
$\mathrm{~F}^{-}$ & $<10^{-5}$ \\
$\mathrm{CH}_{3} \mathrm{COO}^{-}$ & $<10^{-5}$ \\
$\mathrm{SO}_{4}{ }^{2-}$ & $2.5 \times 10^{-5}$ \\
$\mathrm{I}^{-}$ & $3.0 \times 10^{-4}$ \\
$\mathrm{Cl}^{-}$ & $1.5 \times 10^{-5}$ \\
$\mathrm{SCN}^{-}$ & $1.5 \times 10^{-4}$ \\
$\mathrm{CN}^{-}$ & $4.0 \times 10^{-4}$ \\
$\mathrm{SO}_{3}{ }^{2-}$ & $1.7 \times 10^{-5}$ \\
\hline
\end{tabular}

that the proposed triiodide membrane sensor is highly selective with respect to most common organic and inorganic anions such as fluoride, chloride, bromide, iodide, nitrate, nitrite, sulfite, sulfate, and thiocyanate. Table 2 reveales that, the selectivity coefficients for all anions tested are $10^{-5}$ or smaller (except iodide and thiocyanate with $10^{-4}$ ), which seems to indicate that these anions have negligible disturbances on the functioning of the triiodide membrane electrode. The surprisingly high selectivity of the membrane electrode for triiodide ion over other anions used, most probably arises from the strong tendency of the carrier molecule SB for triiodide ion in the form of the (SB-I $\left.{ }^{+}\right) \mathrm{I}_{3}{ }^{-}$ adduct, as well as the kinetically, and thermodynamically, favored salt molecule matrix reaction between iodide ion and iodine, which results in the formation of a stable $\mathrm{I}_{3}^{-}$ion in solution. ${ }^{27}$

Table 3, compares some of the selectivity coefficients, detection limits, and linearity concentration ranges of the best previously reported triiodide ion-selective electrodes based on different ion-carrier with those obtained for the proposed triiodide electrode based on ICT. As is immediately obvious from Table 3 , not only in terms of detection limit and working concentration range, but also in terms of selectivity coefficients, the proposed triiodide sensor is superior to those reported for other triiodide ion-selective electrodes. $^{25-30}$

The proposed triiodide membrane sensor was found to work well under laboratory conditions. It was successfully used as an indicator electrode to the titration of $25.0 \mathrm{~mL}$ of a $1.0 \times 10^{-4} \mathrm{M}$ triiodide solution with a $1.0 \times 10^{-2} \mathrm{M}$ sodium thiosulfate solution and the resulting titration curve is shown in Figure 6. As can be seen, the amount of triiodide ions in solution can be determined with the electrode.

It is worth mentioning that the membrane electrode may

Table 3. Comparison some of the selectivity coefficients, and detection limit, and linearity concentration range

\begin{tabular}{cccr}
\hline Reference & LDR & DL & $\mathrm{K}^{\mathrm{SCN}}$ \\
\hline 25 & $8.0 \times 10^{-6}-5.0 \times 10^{-3}$ & $5.0 \times 10^{-6} \mathrm{M}$ & $1.20 \times 10^{-3}$ \\
26 & $7.0 \times 10^{-6}-2.0 \times 10^{-3}$ & $3.0 \times 10^{-6} \mathrm{M}$ & $5.01 \times 10^{-3}$ \\
27 & - & - & $2.51 \times 10^{-3}$ \\
29 & $7.9 \times 10^{-6}-1.0 \times 10^{-1}$ & $6.0 \times 10^{-6} \mathrm{M}$ & $2.50 \times 10^{-4}$ \\
30 & $1.0 \times 10^{-5}-1.0 \times 10^{-1}$ & $1.0 \times 10^{-6} \mathrm{M}$ & $3.09 \times 10^{-3}$ \\
This Work & $5.0 \times 10^{-7}-5.0 \times 10^{-2}$ & $3.0 \times 10^{-7} \mathrm{M}$ & $6.00 \times 10^{-2}$ \\
\hline
\end{tabular}




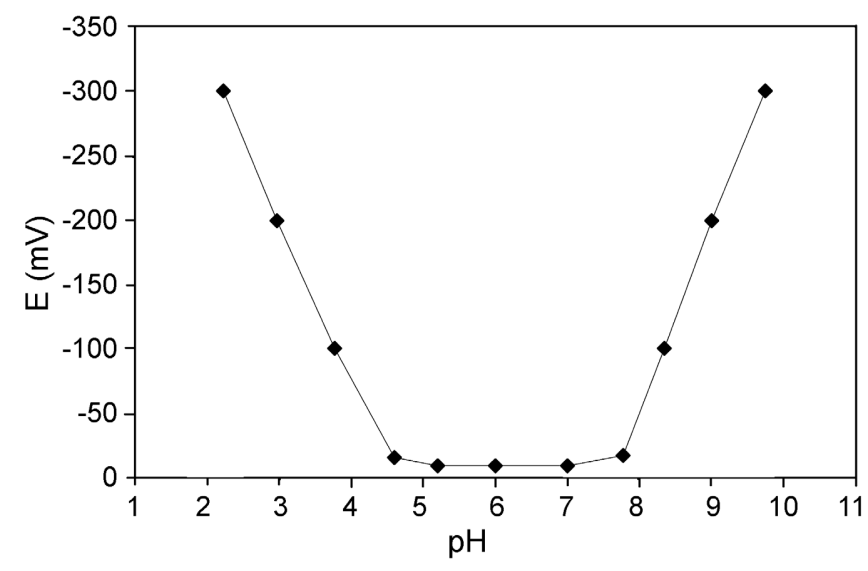

Figure 5. The effect of the $\mathrm{pH}$ of the test solutions on the potential response of the electrode based on ICT (No. 3).

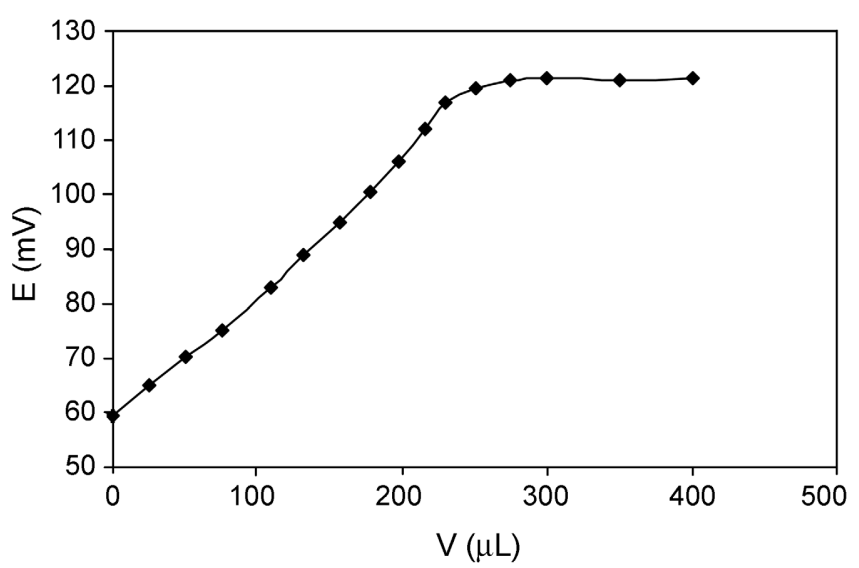

Figure 6. Titration curve of triiodide with thisolfate.

possibly be used for the determination of ozone, after the oxidation of iodide to triiodide ion. The use of a triiodide ion-selective electrode for this purpose might be simpler than the use of disposable ozonesondes based on the coulometric oxidation of the iodide to triiodide ion, which are usually used for the determination of ozone.

\section{References}

1. Hofmeister, P. Arch. Exp. Pathol. Pharmacol. 1888, 24, 247.

2. Yuan, R.; Chai, Y. Q.; Liu, D.; Gao, D.; Li, J. Z.; Yu, R. Q. Anal. Chem. 1993, 65, 2572.

3. Gao, D.; Li, J. Z.; Yu, R. Q.; Zheng, G. D. Anal. Chem. 1994, 66, 2245.

4. Ying, M.; Yuan, R.; Zhang, X. M.; Song, Y. Q.; Li, Z. Q.; Shen, G. L.; Yu, R. Q. Analyst 1997, 122, 1143.

5. Li, Z. Q.; Yuan, R.; Ying, M.; Song, Y. Q.; Shen, G. L.; Yu, R. Q. Anal. Lett. 1997, 30, 1455.

6. Chaniotakis, N. A.; Jurkschat, K.; Ruhlemann, A. Anal. Chim. Acta 1993, 282, 345.

7. Hisamoto, H.; Siswanta, D.; Nishihara, H.; Suzuki, K. Anal. Chim. Acta 1995, 304, 171.

8. Badr, I. H. A.; Meyerhoff, M. K.; Hassan, S. S. M. Anal. Chem. 1995, 67, 2613.

9. Rothmaier, M.; Schaller, U.; Morf, W. E.; Pretsch, E. Anal. Chim. Acta 1996, 327, 17.

10. Jyo, A.; Minakami, R.; Kanda, Y.; Egawa, H. Sens. Actuators $B$ 1993, 13, 200.
11. Blair, T. L.; Allen, J. R.; Daunert, S.; Bachas, L. G. Anal. Chem. 1993, 65, 2155.

12. Gao, D.; Gu, J.; Yu, R. Q.; Zheng, G. D. Analyst 1995, 120, 499.

13. Malinowska, E.; Meyerhoff, M. E. Anal. Chim. Acta 1995, 300, 33.

14. Sun, C. Q.; Zhao, J. H.; Xu, H. D.; Sun, Y. P.; Zhang, X.; Shen, J. C. Talanta 1998, 46, 15.

15. Ganjali, M. R.; Pourjavid, M. R.; Poursaberi, T.; Rezapour, M.; Javanbakht, M.; Sharghi, H. Anal. Sci. 2003, 19, 995.

16. Ganjali, M. R.; Yousefi, M.; Poursaberi, T.; Naji, L.; SalavatiNiasari, M.; Shamsipur, M. Electroanalysis 2003, 15, 1476.

17. Shamsipur, M.; Rouhani, S.; Mohajeri, A.; Ganjali, M. R.; Rashidi-Ranjbar, P. Anal. Chim. Acta 2000, 418, 197.

18. Ganjali, M. R.; Pourjavid, M. R.; Rezapour, M.; Poursaberi, A.; Salavati-Niasari, M. Anal. Lett. 2003, 36, 881 .

19. Poursaberi, T.; Hossieni, M.; Taghizadeh, M.; Pirelahi, H.; Shamsipur, M.; Ganjali, M. R. Microchem. J. 2002, 72, 77.

20. Ganjali, M. R.; Mizani, F.; Emami, M.; Salavati-Niasari, M.; Shamsipour, M.; Yousefi, M.; Javanbakht, M. Electroanaysis 2003, 15, 139 .

21. Ganjali, M. R.; Mizani, F.; Salavati-Niasari, M. Anal. Chim. Acta 2003, 481, 85.

22. Farhadi, K.; Maleki, R. Anal. Sci. 2002, 18, 133.

23. Farhadi, K.; Maleki, R.; Shamsipur, M. Electroanalysis 2002, 14, 760.

24. Suzuki, H.; Nakagawa, H.; Minfune, M.; Saito, Y. Anal. Sci. 1993, 9, 351

25. Ganjali, M. R.; Shamsipur, M.; Emami, M.; Salavati-Niasari, M.; Javanbakht, M.; Yousefi, M. Sens. Actuators B 2005, 105, 127.

26. Farhadi, K.; Bonab, H. S.; Maleki, R.; Shamsipur, M.; Sharghi, H. J. Chin. Chem. Soc. 2002, 49, 861.

27. Rouhollahi, A.; Shamsipur, M. Anal. Chem. 1999, 71, 1350

28. Sadeghi, S.; Dashti, G. R. Anal. Chem. 2002, 74, 2591.

29. Kamata, S.; Bhale, A.; Fukunaga, Y.; Murata, H. Anal. Chem. 1988, 60, 2464

30. Yang, X. H.; Kumar, N.; Chi, H.; Hibbert, D. B.; Alexander, P. W. Electroanalysis 1997, 9, 549.

31. Zare, H. R.; Ardakani, M. M.; Nasirizadeh, N.; Safari, J. Bull. Korean Chem. Soc. 2005, 26, 51.

32. Ganjali, M. R.; Matloobi, P.; Ghorbani, M.; Norouzi, P.; SalavatiNiasari, M. Bull. Korean Chem. Soc. 2005, 26, 38.

33. Ganjali, M. R.; Zamani, H. A.; Norouzi, P.; Adib, M.; Rezapour, M.; Aceedy, M. Bull. Korean Chem. Soc. 2005, 26, 57934

34. Tavakkoli, N. Bull. Korean Chem. Soc. 2004, 25, 1474.

35. Ganjali, M. R.; Ghorbani, M.; Daftari, A.; Norouzi, P.; Pirelahi, H.; Dargahani, H. D. Bull. Korean Chem. Soc. 2004, 25, 172.

36. Ganjali, M. R.; Babaei, L. H.; Taghvaei-Ganjali, S.; Modjallal, A.; Shamsipur, M.; Hosseini, M.; Javanbakht, M. Bull. Korean Chem. Soc. 2004, 25, 77 .

37. Ganjali, M. R.; Pourjavid, M. R.; Mouradzadegun, K.; Hosseini, M.; Mizani, F. Bull. Korean Chem. Soc. 2003, 24, 1585.

38. Ganjali, M. R.; Daftari, A.; Mizani, F.; Salavati-Niasari, M. Bull. Korean Chem. Soc. 2003, 24, 23.

39. Ganjali, M. R.; Emami, M.; Salavati-Niasari, M. Bull. Korean Chem. Soc. 2002, 23, 1394

40. Schaller, U.; Bakker, E.; Spichiger, U. E.; Pretsch, E. Anal. Chem. 1994, 66, 391

41. Ammann, D.; Pretsch, E.; Simon, W.; Lindner, A.; Bezegh, A.; Pungor, E. Anal. Chim. Acta 1985, 171, 119.

42. Eugster, R.; Spichiger, U. E.; Simon, W. Anal. Chem. 1993, 65, 689.

43. IUPAC Analytical Chemistry Revision, Commission on Analytical Nomenclature Recommendations for Nomenclature of Ion Selective Electrodes. Pure Appl. Chem. 1976, 48, 127.

44. Christian, G. D. Analytical Chemistry; Wiley \& Sons: New York, 1986 (ISBN: 0-471-21472-8)

45. Umezawa, Y.; Umezawa, K.; Sato, H. Pure Appl. Chem. 1995, 67, 507.

46. Rouhollahi, A.; Kakanejadifard, A.; Farnia, S. M. F.; Shamsipur, M. Polish J. Chem. 1997, 71, 731.

47. Myers, O. E. J. Chem. Phys. 1958, 28, 1027. 